\title{
Development and Validation of an Eco-friendly HPLC- UV-DAD Method for the Determination of Allopurinol in Pharmaceuticals with Application to In vitro Dissolution Studies
}

\author{
Anderson Silva de Oliveira ${ }^{1}$ (D), João Luis Silva de Oliveira ${ }^{2(D)}$, Fernanda de Souza Dias ${ }^{2(D)}$, Laura \\ Beatriz Souza e Souza ${ }^{2}$ (D), Débora de Andrade Santana ${ }^{1}$ (D), Aníbal de Freitas Santos Júnior 1, 2, *(D) \\ 1 Department of Exact and Earth Sciences (DCET), State University of Bahia, 41195-000, Salvador-BA, Brazil \\ 2 Department of Life Sciences (DCV), State University of Bahia, 41195-000 Salvador-BA, Brazil \\ * Correspondence: afjunior@uneb.br;
}

Received: 5.01.2021; Revised: 28.01.2021; Accepted: 31.01.2021; Published: 7.02.2021

\begin{abstract}
In this study, a sustainable HPLC-UV-DAD method was developed and validated for the determination of allopurinol in tablets and optimization of the dissolution test using factorial design. The separation of the analyte from the sample matrix was achieved in 3.01 minutes in a C8 column (4.6 $\mathrm{mm} X 150 \mathrm{~mm} \mathrm{X} 5 \mu \mathrm{m})$, using mobile phase $0.1 \mathrm{~mol} \mathrm{~L}^{-1} \mathrm{HCl}(25 \%)+$ ethanol $(50 \%)+$ ultrapure water $(25 \%)$ by UV detection at $249 \mathrm{~nm}$. The method presented satisfactory analytical parameters of validation (specificity, selectivity, linearity, stability, precision, accuracy, and robustness), showing no matrix effects. The dissolution test was optimized by complete factorial design $2^{3}$ and, the optimal conditions were: $\mathrm{HCl} 0.001 \mathrm{~mol} \mathrm{~L}^{-1}$, apparatus II (paddle) and $75 \mathrm{rpm}$. The analytical procedures and dissolution tests were applied to allopurinol tablets marketed in Bahia, Brazil, to evaluate the dissolution studies. The pharmaceuticals had similar dissolution profiles and first-order dissolution kinetics. This new and sustainable HPLC-UV-DAD method is friendly to the environment and can be used for the routine pharmaceutical analysis of allopurinol in fixed dosage forms.
\end{abstract}

Keywords: allopurinol; eco-friendly HPLC-UV-DAD method; factorial design; dissolution; pharmaceutical and chemical analysis.

(C) 2021 by the authors. This article is an open-access article distributed under the terms and conditions of the Creative Commons Attribution (CC BY) license (https://creativecommons.org/licenses/by/4.0/).

\section{Introduction}

Allopurinol is a drug used in treating idiopathic gout, lithiasis, and acute nephropathy induced by uric acid. In neoplastic or myeloproliferative diseases, after its treatment with cytotoxic agents, increase blood levels of urates. It is the natural isomer of hypoxanthine that inhibits the enzyme hypoxanthine oxidase. Its main metabolite oxypurinol decreases the levels of uric acid in plasma and urine [1]. Chemically denominated as $1 \mathrm{H}, 2 \mathrm{H}, 4 \mathrm{H}$-pyrazolo [3,4-d] pyrimidin-4-one (Figure 1), allopurinol is soluble in water, ethanol, and chloroform, presenting an increment in solubilization with an increase in the $\mathrm{pH}$ of the solvent and also has stability in exposure to light and moisture [2,3]. There is a controversy about its classification in the biopharmaceutical classification system, is classified as class 4 (low solubility and low permeability) by the Drug Delivery Foundation (DDF) and class 1 (high solubility and high permeability) $[4,5]$. 
<smiles>O=c1ncnc2[nH][nH]cc1-2</smiles>

Figure 1. Molecular structure of the allopurinol.

In Brazil, allopurinol is available on the market as tablets (100 $\mathrm{mg}$ and $300 \mathrm{mg}$ ), totaling 17 presentations (02 reference and 15 generic drugs) [6]. Pharmacopeias determine the tests that must be performed on the active pharmaceutical ingredient and the pharmaceutical forms. In the absence of information in the compendiums, industries must adopt other official pharmacopeias or develop and validate methods capable of identifying and quantifying the drugs presented in the most diverse pharmaceutical forms and in their active pharmaceutical ingredients [7-9]. In addition, these methods must respect the principles of green chemistry, with the elimination and/or reduction in the use of solvents toxic to the environment, decreasing the environmental impact of pollutants' emission and contributing to a sustainable environment [10]. Furthermore, analytical techniques, such as high-performance liquid chromatography (HPLC) and molecular absorption spectrophotometry in the ultraviolet (UV) region, in combination with chemometric tools, are used for drug analysis due to its advantages and low solvent consumption [11-13]. However, there are still toxic and environmentally unsustainable solvents, such as methanol and acetonitrile [14-18].

The speed and dissolution rate of dissolution is decisive for the release and absorption of a drug from a solid oral pharmaceutical form. Therefore, the dissolution kinetics study is very important and, dissolution testing has been used primarily as a quality control test for solid oral drug products [19-24]. The dissolution test determines the percentage of the active pharmaceutical ingredient released in the dissolution medium as a function of time, using the label's quantity as a marker. Also, it demonstrates whether the product meets the criteria defined in the studied drug monograph through an in vitro prediction ratio of bioavailability $[25,26]$. To assess the quality of medicines, the dissolution profile is compared with the reference medicine. This test is performed by collecting multipoint and the dissolution test's execution to determine if the dissolution profiles of the two drugs tested are statistically comparable to evaluate the pharmaceutical equivalence [27-29].

Therefore, this study aimed to develop and validate an efficient, rapid, and sustainable HPLC-UV-DAD method, combined with chemometric tools, for the determination of allopurinol and obtain the dissolution profiles of allopurinol tablets. In addition to proposing a green and environmentally sustainable method, this new method could also be used for the routine analysis of allopurinol in fixed dosage pharmaceutical forms. The method was validated according to guidelines and applied for the assay of allopurinol tablets.

\section{Materials and Methods}

\subsection{Reagents and materials.}

All chemical reagents used in experiments were gradient grad (Quimex®, Merck, Brazil). Allopurinol reference chemical substance (RCS) was purchased from Brazilian Pharmacopoeia, through the National Quality Control Institute of the Oswaldo Cruz Foundation (FIOCRUZ, Brazil), with $100.0 \%$ purity, calculated concerning the desiccated 
substance and determined by HPLC. For the preparation of all standard solutions and samples, ultrapure water (with resistivity $18 \mathrm{M} \Omega \mathrm{cm}^{-1}$ ) obtained from the Milli-Q Pluswater purification system (Millipore Molsheim, France) was used. All laboratory glassware was washed in a 10\% $\left(\mathrm{v} \mathrm{v}^{-1}\right) \mathrm{HNO}_{3}$ solution for $24 \mathrm{~h}$, rinsed with high-purity water, and dried at ambient temperature. Nylon filters with $0.22 \mu \mathrm{m}$ pores (Agilent, USA) were used to filter the samples. Allopurinol tablets, containing 100 and $300 \mathrm{mg}$ (reference and generic products, designed as Z1, Z2, M1, M2, S, and P), were purchased from pharmacies located in Salvador and Santo Amaro da Purificação, Bahia, Brazil. All tests were performed on products within the expiration date.

\subsection{Instruments.}

A high-performance liquid chromatography (Shimadzu scientific instruments, Kyoto, Japan), outstanding model, equipped with high-pressure quaternary pump (Model LC-20AD), degasser (model DGU-20A5), diode array detector (Model SPD-20A), sampler automatic (model SIL-20A), column heating oven (model CTO-20A) and, a communication module (model CBM-20A) and operated by the LC solutions software, was used. The used column (stationary phase) C8 column (150 mm X $4.6 \mathrm{~mm}$ X $5.0 \mu \mathrm{m})$ was purchased from Shimadzu, Barueri, SP, and Brazil. The dissolution tests were performed in the dissolving equipment (Ethik, Model 299, Vargem Grande Paulista, SP, Brazil) with a manual collection of aliquots $(10 \mathrm{~mL})$, at the determined times and replacement of the dissolution medium. The determination of tablet weight, content uniformity, and allopurinol dosage were performed using the analytical balance (M164-AI Mark®, Piracicaba, SP, Brazil). The friability test used the friabilometer equipment (Ethik, Model HX 300-2, Vargem Grande Paulista, SP, Brazil) and, the disintegration test was performed on the disintegrator (Nova Ética, Modelo 301 / AC01, Vargem Grande Paulista, SP, Brazil).

\subsection{Chromatographic conditions.}

To define the chromatographic conditions and to solubilize the RCS allopurinol, $20 \mu \mathrm{L}$ of solutions containing RCS allopurinol $\left(1.0 \mu \mathrm{g} \mathrm{mL}^{-1}\right)$ were injected using the solvents: ethanol, $\mathrm{HCl}\left(0.1 \mathrm{~mol} \mathrm{~L}^{-1}\right), \mathrm{NaOH}\left(0.1 \mathrm{~mol} \mathrm{~L}^{-1}\right)$, and methanol, with mobile phase methanol and ultrapure water (50: 50, $\left.\mathrm{v} \mathrm{v}^{-1}\right)$. Then, the composition of the mobile phase was evaluated: ethanol + ultrapure water $\left(50: 50 \mathrm{v} \mathrm{v}^{-1}\right)$; ethanol + ultrapure water $\left(70: 30 \mathrm{v} \mathrm{v}^{-1}\right) ; 0.1 \mathrm{~mol} \mathrm{~L}^{-1}$ $\mathrm{HCl}+$ ultrapure water $\left(50: 50 \mathrm{v} \mathrm{v}^{-1}\right)$; ethanol $+0.1 \mathrm{~mol} \mathrm{~L}^{-1} \mathrm{HCl}\left(50: 50 \mathrm{v} \mathrm{v}^{-1}\right)$; and, $0.1 \mathrm{~mol} \mathrm{~L}^{-1}$ $\mathrm{HCl}+$ ethanol + ultrapure water $\left(25: 50: 25 \mathrm{v} \mathrm{v}^{-1}\right)$, checking which flow had the best separation between peaks. The flow rate of the mobile phase was investigated from 0.6 to $0.9 \mathrm{~mL} \mathrm{~min}{ }^{-1}$. After optimization, $20 \mu \mathrm{L}$ of the solution containing the RCS allopurinol $\left(1.0 \mu \mathrm{g} \mathrm{mL}^{-1}\right)+1 \%$ solution $\left(\mathrm{w} \mathrm{v}^{-1}\right)$ of excipients (lactose, starch, croscarmellose sodium, microcrystalline cellulose, macrogol, crospovidone, povidone, polyvinylpyrrolidone, and magnesium stearate) contained in the formulation of the tablets, were injected to assess selectivity. Retention time $(\mathrm{Rt})$, retention factor $(\mathrm{k})$, the number of theoretical plates $(\mathrm{N})$, and chromatographic resolution (R) were calculated.

\subsection{Analytical validation.}

The method was validated through the analysis of specificity, selectivity, linearity, stability, precision, accuracy, limits of detection (LOD) and quantification (LOQ), and robustness, in accordance with the protocols suggested by the International Conference on 
Harmonisation ( $\mathrm{ICH})$ and International Union of Pure and Applied Chemistry (IUPAC) recommendations [30,31].

Specificity and selectivity were evaluated by the exclusive analytical response of the analyte (allopurinol) without interference from excipients, matrix, impurities, or degradation products. The analytical signals of the mobile phase and $1 \%$ solution $\left(\mathrm{w} \mathrm{v}^{-1)}\right.$ of excipients (placebo) were evaluated, and, therefore, well-shaped peaks also indicate the specificity of the method. Linearity was determined by the correlation coefficients of the analytical curves generated (concentrations of allopurinol versus the peak area was constructed) by the injections (triplicate) of the working solutions at five concentration levels. The solutions and samples' stabilities were evaluated by checking possible changes in the analytical signal after HPLC analysis for $24 \mathrm{~h}$, at room temperature, and kept at $37^{\circ} \mathrm{C}$. Triplicate averages with a standard deviation (RSD) lower than $10 \%$ were considered satisfactory for evaluating the precision. A known amount of RCS allopurinol $\left(0.5 \mu \mathrm{g} \mathrm{mL} \mathrm{mL}^{-1}\right)$ was added to a sample solution (Z1). Recoveries (> 80\%) were considered satisfactory for assessing the accuracy of the proposed method. Robustness was evaluated from the flow of the mobile phase variations $(0.6 ; 0.7 ; 0.8$ and $0.9 \mathrm{~mL} \mathrm{~min}^{-1}$ ) by RSD (\%) of measurements in triplicate. The limits of detection and quantification were estimated using the following equations: $\mathrm{LOD}=3.3 \times \mathrm{SDb} / \mathrm{a}$ and $\mathrm{LOQ}=$ $10 \times \mathrm{SDb} / \mathrm{a}$, respectively, where $\mathrm{SDb}$ is the standard deviation of the intercept and a is the slope of the regression line [32].

Table 1. Variables and levels were used in the experimental design and complete factorial design $2^{3}$ with 6

\begin{tabular}{|c|c|c|c|}
\hline \multirow[t]{2}{*}{ Variables } & \multicolumn{3}{|c|}{$\begin{array}{l}\text { repetitions of the central point. } \\
\text { Levels }\end{array}$} \\
\hline & -1 & 0 & $\mathbf{1}$ \\
\hline Rotation (rpm) & 50 & 75 & 100 \\
\hline$[\mathrm{HCl}]\left(\mathrm{mol} \mathrm{L}^{-1}\right)$ & 0.001 & 0.01 & 0.1 \\
\hline Apparatus & basket & $\begin{array}{l}\text { basket or } \\
\text { paddle }\end{array}$ & paddle \\
\hline \multicolumn{4}{|c|}{ Complete factorial design $2^{3}$} \\
\hline Experiment & rpm & {$[\mathrm{HCl}]$} & apparatus \\
\hline 1 & $-1(50)$ & $-1(0.001)$ & -1 (basket) \\
\hline 2 & $+1(100)$ & $-1(0.001)$ & -1 (basket) \\
\hline 3 & $-1(50)$ & $+1(0.1)$ & -1 (basket) \\
\hline 4 & $+1(100)$ & $+1(0.1)$ & -1 (basket) \\
\hline 5 & $-1(50)$ & $-1(0.001)$ & +1 (paddle) \\
\hline 6 & $1(100)$ & $-1(0.001)$ & +1 (paddle) \\
\hline 7 & $-1(50)$ & $+1(0.1)$ & +1 (paddle) \\
\hline 8 & $+1(100)$ & $+1(0.1)$ & +1 (paddle) \\
\hline $9(\mathrm{C})$ & $0(75)$ & $0(0.01)$ & 0(basket) \\
\hline $10(\mathbf{C})$ & $0(75)$ & $0(0.01)$ & 0 (basket) \\
\hline $11(\mathrm{C})$ & $0(75)$ & $0(0.01)$ & O(basket) \\
\hline $12(\mathrm{C})$ & $0(75)$ & $0(0.01)$ & 0 (paddle) \\
\hline $13(\mathrm{C})$ & $0(75)$ & $0(0.01)$ & 0 (paddle) \\
\hline $14(\mathrm{C})$ & $0(75)$ & $0(0.01)$ & 0 (paddle) \\
\hline
\end{tabular}

\subsection{Dissolution studies.}

Brazilian Pharmacopoeia [8] did not indicate methodologies for allopurinol dissolution tests. Only in 2019, with the publication of its sixth edition, methods using molecular absorption spectrophotometry in the ultraviolet region (UV) for quality control of allopurinol (identification, dissolution, and dosage tests) were introduced. Currently, the Brazilian and United State (USP) [33] pharmacopeias recommend the use of UV spectrophotometric methods for the dissolution test for allopurinol in tablets, under the following conditions: $900 \mathrm{~mL}$ hydrochloric acid $(\mathrm{HCl}) 0.01 \mathrm{~mol} \mathrm{~L}^{-1}$; apparatus 2 (paddle), with a rotational speed of 75 
rotations per minute (rpm), for 45 minutes. Therefore, this study aims to develop and validate an unedited and sustainable HPLC-UV-DAD method to evaluate this drug's dissolution. For the allopurinol dissolution test, in tablets, a complete factorial design $2^{3}$ was carried out, with 6 central points, with the following variables studied: concentration of the dissolution medium $\left(0.1 ; 0.01\right.$ and $\left.0.001 \mathrm{~mol} \mathrm{~L}^{-1} \mathrm{HCl}\right)$, in a volume of $900 \mathrm{~mL}$; the speed of rotation of the dissolver (50, 75 and $100 \mathrm{rpm}$ ); and, the type of apparatus [type 1 (basket) and type 2 (paddle)] during 45 minutes and, the optimal conditions for drug determination were established (Table 1).

After optimizing the proposed dissolution test for allopurinol, the allopurinol tablets (Z1, Z2, M1, M2, S, and P) were submitted to the dissolver obtain the dissolution profiles. 10 $\mathrm{mL}$ of sample was withdrawn and replaced with fresh dissolution medium at the time intervals of $0,1,3,5,10,15,20,30,40,45,60,75$, and 90 minutes. The aliquots were filtered, and the concentrations of allopurinol in samples were determined by the proposed HPLC-UV-DAD method. The profiles were compared using the method based on ANOVA (factors: $f_{1}$ and $f_{2}$ ), dependent model method (definition of zero-order and first-order models) with the construction of time (minutes) versus the quantity of undissolved allopurinol. The correlation coefficient $(\mathrm{r})$, dissolution rate constant $(\mathrm{k})$, dissolution half-life ( $\left.\mathrm{t}_{50 \%}\right)$, and dissolved amount of allopurinol were calculated after 45 minutes of dissolution test $\left(\mathrm{Q}_{45}\right)$. Also, the dissolution efficiency (ED\%) was calculated using the trapezoid method. Weight uniformity, friability, and disintegration time were determined according to Brazilian [8] and USP [33] pharmacopeias.

\section{Results and Discussion}

\subsection{Analytical performance and validation.}

The HPLC-UV-DAD proposed method was validated to provide analytical applications for the dissolution test's rapid quality control analysis. The results showed that the proposed method met the validation requirements defined by the guidelines (Table 2), presented good linearity and homoscedasticity, showing no matrix effects. Therefore, it is suggested that this proposed method can be used to quantify allopurinol as an active pharmaceutical ingredient and finished product, respecting the limits of the working range.

Table 2. Validation of the method for determination of allopurinol (tablets) using HPLC-UV-DAD.

\begin{tabular}{l|l|l} 
Figures of merit & $\begin{array}{l}\text { Values obtained } \\
(\text { ICH) }\end{array}$ & $\begin{array}{l}\text { Values obtained } \\
\text { (IUPAC) }\end{array}$ \\
\hline Accuracy $(\%)$ & $99.76-99.81$ & $99.79-99.82$ \\
\hline Precision $(\mathrm{RSD}, \%)$ & $<0.50$ & $<0.50$ \\
\hline Detection limit $\left(\mathrm{LOD}, \mu \mathrm{g} \mathrm{mL} \mathrm{mL}^{-1}\right)$ & 0.06 & 0.05 \\
\hline Quantification limit LOQ, $\left(\mu \mathrm{g} \mathrm{mL} \mathrm{mL}^{-1}\right)$ & 0.18 & 0.12 \\
\hline Linearity regression equation & $\mathrm{y}=507223.8 \mathrm{x}+1022446.6$ & $\mathrm{y}=538618.3 \mathrm{x}+1022446.6$ \\
\hline Correlation coefficient $(\mathrm{r})$ & 0.9961 & 0.9976 \\
\hline Determination coefficient $\left(\mathrm{r}^{2}\right)$ & 0.9922 & 0.9952 \\
\hline Linear working range $\left(\mu \mathrm{gL}^{-1}\right)$ & $0.18-0.80$ & $0.12-0.80$ \\
\hline Robustness $(\mathrm{RSD}, \%)$ & $<1.90$ & $<2.00$
\end{tabular}

\subsection{HPLC-UV-DAD method and applications.}

Among the medium for the RCS allopurinol solubilization, ethanol and $0.1 \mathrm{~mol} \mathrm{~L}^{-1} \mathrm{HCl}$ showed satisfactory results (Figure 2), at 210 and $249 \mathrm{~nm}$ wavelengths. In all studies consulted in the literature, the solvents used in the solubilization of allopurinol were methanol and acetonitrile. The present study proposes using an alternative solvent, friendly to the environment, through a new sustainable and efficient method. Thus, $0.1 \mathrm{~mol} \mathrm{~L}^{-1} \mathrm{HCl}$ was selected, respecting the spectrograms obtained, green chemistry principles, and similarity with 
gastric fluid. Rajkumar et al. (2014) [16] developed and validated a method for simultaneous determination of allopurinol and lipoic acid $(210$ and $250 \mathrm{~nm})$ in tablets using reverse-phase HPLC, in India. Ammar et al. (2017) [14] used the wavelength of $254 \mathrm{~nm}$ to quantify allopurinol and salicylic acid simultaneously in Egypt. In USP [33], the allopurinol determination is carried out at a wavelength of $230 \mathrm{~nm}$. In this study, the wavelength of 249 $\mathrm{nm}$ was selected for the determination of the allopurinol.

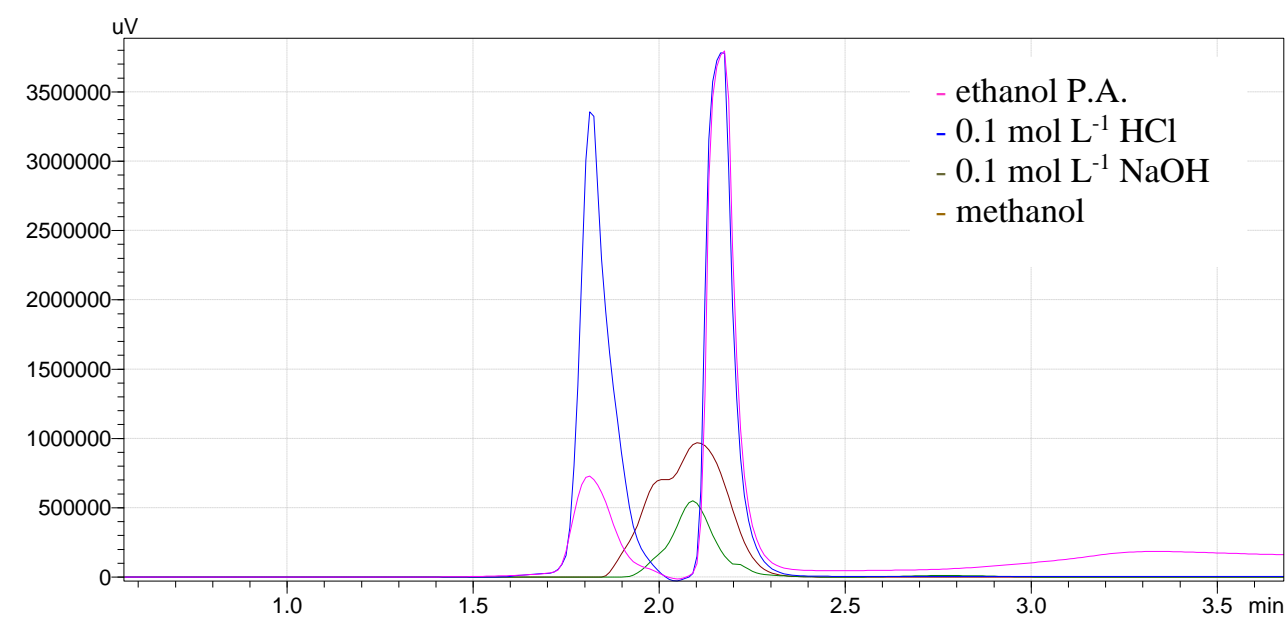

Figure 2. Ideal solubilization medium for allopurinol (RCS and tablets) determination.

The mobile phase $0.1 \mathrm{~mol} \mathrm{~L}^{-1} \mathrm{HCl}+$ ethanol + ultrapure water $\left(25: 50: 25, \mathrm{v} \mathrm{v}^{-1}\right)$ was selected for analysis, as it has lower consumption of pure ethanol solvent, meeting the principles of sustainability. The flow rate of the mobile phase was determined at $0.6 \mathrm{~mL} \mathrm{~min}{ }^{-1}$ (Figure 3). For Jahangirian et al. (2017) [10], the consumption of a smaller proportion of solvents, especially toxic ones, must be one of the questions to be evaluated in the development of methods aiming at the minimum environmental impact to the ecosystem.

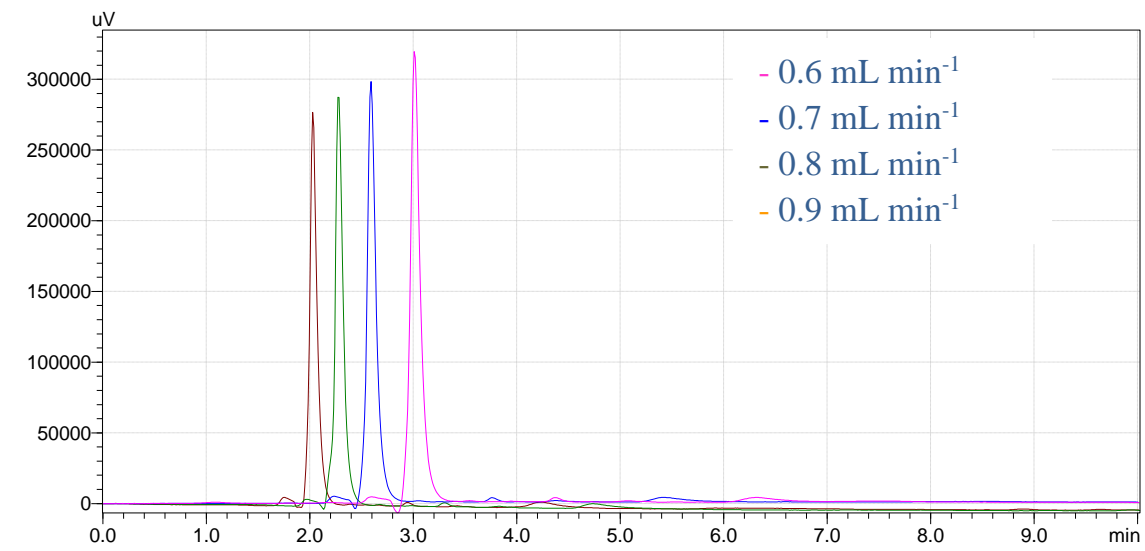

Figure 3. Selection of flow rate of the mobile phase: allopurinol RCS $\left(1.0 \mu \mathrm{g} \mathrm{mL}^{-1}\right)$ chromatograms in $0.1 \mathrm{~mol}$ $\mathrm{L}^{-1} \mathrm{HCl}$.

Rajkumar et al. (2014) [16] used, as a mobile phase, a mixture of aqueous solution of acetic acid + sodium acetate $\left(2.72 \mathrm{~g} \mathrm{~L}^{-1}\right)$ adjusted to $\mathrm{pH} 4.5+$ acetonitrile $\left(96: 4, \mathrm{v} \mathrm{v}^{-1}\right)$. Ammar et al. (2017) [14] used a mixture of acetonitrile + ammonium acetate buffer at $\mathrm{pH} 4.6$ (50:50, $\mathrm{v} \mathrm{v}^{-1}$ ). The Brazilian [8] and USP [33] Pharmacopoeias recommend as media, a mixture of $0.25 \%\left(\mathrm{w} \mathrm{v}^{-1}\right)$ monobasic potassium phosphate aqueous solution + methanol $\left(70: 30, \mathrm{v} \mathrm{v}^{-1}\right)$ and (50: 50, $\mathrm{v} \mathrm{v}^{-1}$ ), respectively. In the literature, no methods were found using this mobile phase to determine allopurinol, being, therefore, one of the innovations of this study. 
The retention time of allopurinol (3.01 minutes), the retention factor (5.20), several theoretical dishes $(6,442)$, and chromatographic resolution (2.05) were calculated, with a running time of 5.0 minutes being defined. It stands out that the running time recommended in the Brazilian [8] and USP [33] Pharmacopoeias for their determinations is 30 and 35 minutes, respectively. Based on these studied parameters, the optimum conditions for allopurinol determination (Table 3) were established.

Table 3. Optimal conditions of HPLC-UV-DAD method for allopurinol (RCS and tablets) determination.

\begin{tabular}{l|l} 
Parameters & Optimal conditions \\
\hline Column & $\mathrm{C} 8(4.6 \mathrm{~mm} \mathrm{X} 150 \mathrm{~mm} \mathrm{X} \mathrm{5 \mu m)}$ \\
\hline Mobile phase & $0.1 \mathrm{~mol} \mathrm{~L}-1 \mathrm{HCl}(25 \%)+$ ethanol $(50 \%)+$ ultrapure water $(25 \%)$ \\
\hline Flow rate $\left(\mathrm{mL} \mathrm{min}^{-1}\right)$ & 0.6 \\
\hline Temperature $\left({ }^{\circ} \mathrm{C}\right)$ & 30 \\
\hline Running time $($ minutes $)$ & 5 \\
\hline Detector & $\mathrm{DAD}(249 \mathrm{~nm})$ \\
\hline Retention time $(\mathrm{Rt}$, minutes $)$ & 3.01
\end{tabular}

\subsection{Dissolution studies.}

After developing and validating the proposed HPLC-UV-DAD method, dissolution studies (test and dissolution profiles) were planned to evaluate the dissolution and release (\%) of allopurinol in tablets. The Brazilian Pharmacopeia [8] indicates that no less than $75 \%$ of the drug is dissolved in 45 minutes. After experimental design and evaluation by the Pareto diagram, it was possible to observe that none variable showed a statistically significant contribution in the dissolution of allopurinol, isolated or in combination (Figure 4).

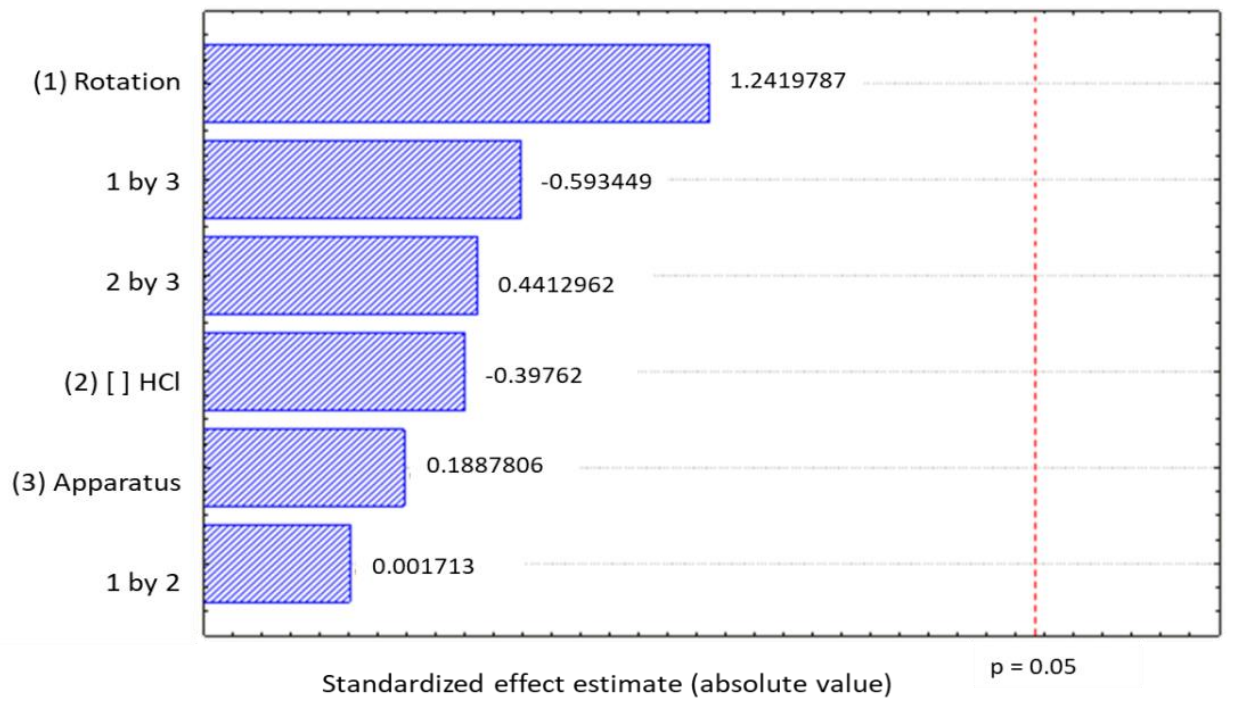

Figure 4. Pareto's diagram of the experimental design for determining the conditions for the allopurinol drug dissolution test.

Thus, the following conditions were selected: dissolution medium $(900 \mathrm{~mL}, 0.001 \mathrm{moL}$ $\mathrm{L}^{-1} \mathrm{HCl}$ ), apparatus type 2 (paddle) and $75 \mathrm{rpm}$ rotation. Furthermore, $50 \mathrm{rpm}$ could be used, but the $75 \mathrm{rpm}$ rotation was selected. It is the same as described in USP [33] and Brazilian [8] Pharmacopoeias. According to the results obtained, this variable did not cause prejudice to the method since this change in the rotation did not interfere with the test results. Also, it is noteworthy that, in the proposed method, the $\mathrm{HCl}$ concentration was ten-fold lower than recommended by pharmacopeias. Multifactorial analysis for determining the optimal conditions of an experiment is extremely important since it is able to establish the best 
conditions for determining an analyte, reducing the number of tests performed and, especially, when a large amount is needed of toxic and environmentally harmful solvents. Moreover, the use of smaller amounts of these solvents has been proposed by the chemical, food, pharmaceutical, and cosmetic industries [10,12,34].

The dissolution test reports, in vitro, the amount of allopurinol dissolved in the reaction medium and, therefore, available to be absorbed in the gastrointestinal tract. Therefore, it is an important test to be evaluated when developing a formulation and in quality control [26]. Tablets containing allopurinol released more than $80 \%$ of allopurinol in 45 minutes $(\mathrm{Z} 1=$ 99.92; $\mathrm{Z} 2=99.11 ; \mathrm{M} 1=99.63 ; \mathrm{M} 2=99.93 ; \mathrm{S}=99.62$ and $\mathrm{P}=99.44 \%$ ) and, therefore, met the criteria defined by the Brazilian [8] and USP [33] pharmacopoeias.

The pharmaceutical dissolution profiles were obtained for the evaluation of pharmaceutical equivalence. The results obtained (Figure 5) demonstrated that allopurinolcontaining drugs (Z1, Z2, M1, M2, S, and P) exhibited comparable dissolution profiles for the drug, according to ANOVA (Table 4). The tested drugs released $\geq 75 \%$ of the drug after 10 minutes of testing. For comparison of the dissolution profiles, the difference factor $\left(\mathrm{f}_{1}\right)$ was calculated among pairs. Similarity factors $\left(\mathrm{f}_{2}\right)$ were not calculated since when the drug has high solubility and provides an immediate release, very fast dissolving technology (dissolving more than $75 \%$ of the drug in less than 15 minutes) for both drugs, the factor $\mathrm{f}_{2}$ loses its discriminative power and, therefore, it is not necessary to calculate it [27].

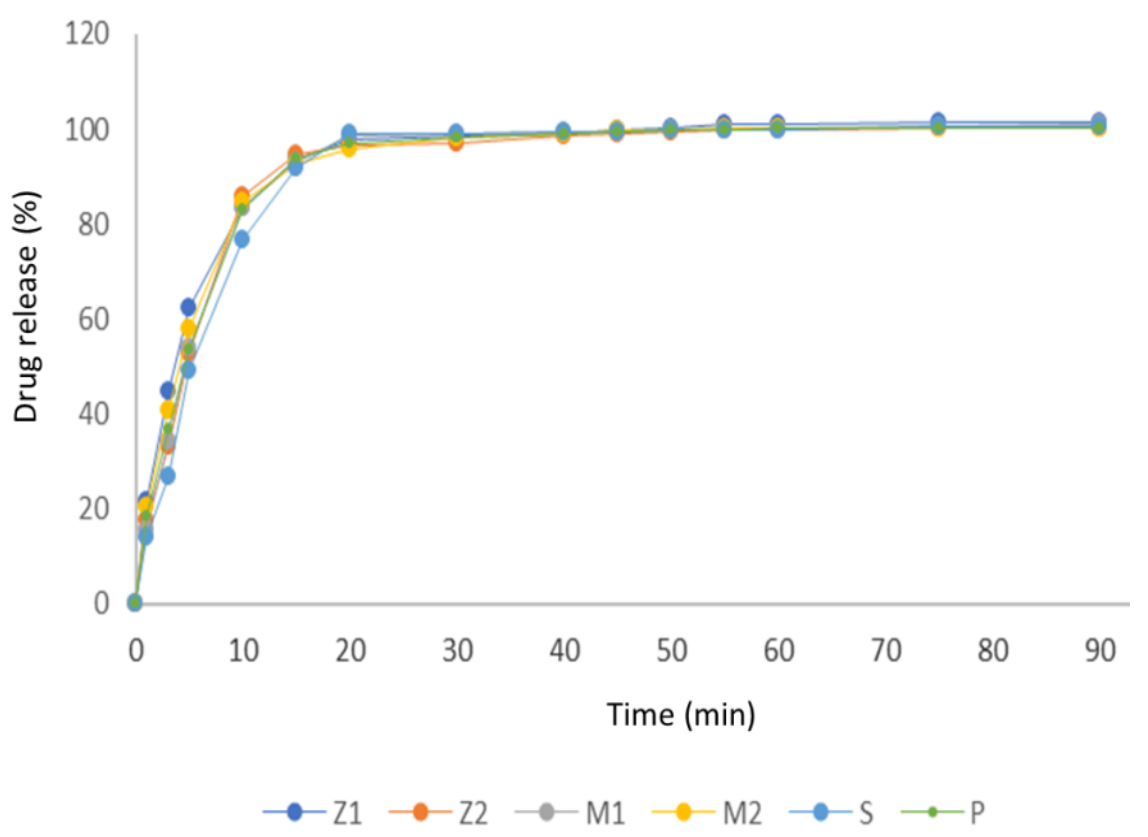

Figure 5. Dissolution profiles of allopurinol tablets (100 and $300 \mathrm{mg}$ ) of products Z1, Z2, M1, M2, S, and P by HPLC-UV-DAD method. (USP type 2 apparatus at $75 \mathrm{rpm}$ with $900 \mathrm{~mL} 0.001 \mathrm{moL} \mathrm{L}^{-1} \mathrm{HCl}$ at $37.0 \pm 0.5^{\circ} \mathrm{C}$ for 90 minutes).

Table 4. Evaluation of variance (ANOVA) of the dissolution profiles of drugs containing allopurinol and $\mathrm{f} 1$ values using HPLC-UV-DAD method.

ANOVA

\begin{tabular}{l|l|l|l|l|l}
\hline Statistical analysis & $\begin{array}{l}\text { Variance } \\
\text { between groups }\end{array}$ & $\begin{array}{l}\text { Variance within } \\
\text { the group }\end{array}$ & F (calculated) & F (critical) & p-value \\
\hline $\begin{array}{l}\text { HPLC-UV-DAD } \\
\text { method }\end{array}$ & 0.008747 & 9.877099 & 0.014878 & 2.323126 & 0.999918 \\
\hline Samples (Drug) & Z1 x M1 & Z1 x S & Z2 x M2 & Z2 x P & \\
\hline$f_{1}$ & 2.18 & 4.05 & 1.29 & 0.48 &
\end{tabular}


Additionally, the zero and first-order kinetic models were calculated for the proposed HPLC-UV-DAD method. The first order dissolution kinetic model adjusted better to this process, showing correlation coefficients closer to 1 compared to zero order. From the model definition, it was possible to determine the parameters: dissolution rate constant $(\mathrm{K})$, dissolution half-life ( $\mathrm{T}_{50 \%}$ ) and, dissolved amount of allopurinol 45 minutes after the start of the dissolution test $\left(\mathrm{Q}_{45}\right)$ (Table 5). The values obtained for $\mathrm{T}_{50 \%}$ of the tested drugs were near (4.56 to 6.81 minutes), corroborating with the data from the dissolution profile analysis (ANOVA and $\mathrm{f}_{1}$ ). In addition, $\mathrm{K}$ varied a little quantity $(0.10$ to 0.22 ), reinforcing that allopurinol's dissolution was very fast in the tablets.

Table 5. Statistical parameters of regression studies, applying models (zero and first-order) by HPLC-UV-DAD method and mean values of kinetic parameters ( \pm standard deviations) from first-order kinetics model, across dissolution profiles of allopurinol.

\begin{tabular}{|c|c|c|c|c|c|c|}
\hline \multicolumn{7}{|c|}{ Dissolution kinetic model } \\
\hline Drug product & Z1 (r) & $\mathbf{Z 2}(\mathrm{r})$ & M1 (r) & M2 (r) & $\mathbf{S}(\mathrm{r})$ & $\mathbf{P}(\mathrm{r})$ \\
\hline Zero order & 0.7041 & 0.7060 & 0.7094 & 0.7071 & 0.7270 & 0.7104 \\
\hline First order & $\mathbf{0 . 9 7 8 2}$ & $\mathbf{0 . 9 7 8 4}$ & 0.9682 & $\mathbf{0 . 9 7 8 2}$ & 0.9669 & $\mathbf{0 . 9 7 9 0}$ \\
\hline \multicolumn{7}{|c|}{ Kinetic parameters ( \pm standard deviations) from first-order kinetics model } \\
\hline Drug product & \multicolumn{2}{|c|}{$\mathbf{T}_{50 \%}$ (minutes) } & \multicolumn{2}{|c|}{$\mathbf{Q}_{45}(\%)$} & \multicolumn{2}{|c|}{ K (minutes $\left.{ }^{-1}\right)$} \\
\hline $\mathrm{Z} 1$ & \multicolumn{2}{|c|}{$4.99( \pm 0.27)$} & \multicolumn{2}{|c|}{$99.82( \pm 5.76)$} & \multicolumn{2}{|c|}{$0.14( \pm 0.01)$} \\
\hline $\mathrm{Z} 2$ & \multicolumn{2}{|c|}{$6.81( \pm 0.35)$} & \multicolumn{2}{|c|}{$99.07( \pm 4.51)$} & \multicolumn{2}{|c|}{$0.10( \pm 0.01)$} \\
\hline M1 & \multicolumn{2}{|c|}{$5.82( \pm 0.49)$} & \multicolumn{2}{|c|}{$99.56( \pm 9.77)$} & \multicolumn{2}{|c|}{$0.12( \pm 0.02)$} \\
\hline M2 & \multicolumn{2}{|c|}{$4.56( \pm 0.33)$} & \multicolumn{2}{|c|}{$99.86( \pm 4.17)$} & \multicolumn{2}{|c|}{$0.15( \pm 0.01)$} \\
\hline $\mathrm{S}$ & \multicolumn{2}{|c|}{$4.75( \pm 0.52)$} & \multicolumn{2}{|c|}{$99.49( \pm 8.96)$} & \\
\hline $\mathrm{P}$ & \multicolumn{2}{|c|}{$5.17( \pm 0.19)$} & \multicolumn{2}{|c|}{$99.41( \pm 3.20)$} & \multicolumn{2}{|c|}{$\frac{0.15( \pm 0.02)}{0.13( \pm 0.01)}$} \\
\hline
\end{tabular}

r: correlation coefficient

Moghal et al. (2016) [35] determined the kinetic dissolution model of allopurinol in the immediate release tablets developed in Savar Dakar, Bangladesh. Of the 09 drugs tested, 07 presented the first-order model like the one that best explains the dissolution of formulated drugs, corroborating this study's findings. Ammar et al. (2017) [14] performed the dissolution test on four drugs using the $0.1 \mathrm{~mol} \mathrm{~L}^{-1} \mathrm{HCl}$ medium and established the dissolution kinetics. Of those analyzed, two presented a first-order model for dissolution of allopurinol, one of them, the reference drug $(100 \mathrm{mg})$.

Dissolution efficiency (DE,\%) of allopurinol (106.03 - 107.66\%) in the analyzed drugs was calculated using the trapezoids rule, according to the established criterion $(\geq 75 \%$, in 45 minutes), in Brazilian [8] and USP [33] pharmacopeias. Alghadi and Hamedelneil (2017) [5] studied the immediate release of allopurinol in $0.1 \mathrm{~mol} \mathrm{~L}^{-1} \mathrm{HCl}$, in tablets sold in Sudan. Only one drug product had a dissolution percentage below 75\% of the allopurinol, in 15 minutes of testing. All other medicines showed drug release $>90 \%$ in 15 minutes. Moghal et al. (2016) [35] evaluated the in vitro release of allopurinol in the immediate release tablets developed in Bangladesh, using as excipients croscarmellose sodium, lactose, microcrystalline cellulose, crospovidone, talc, and magnesium stearate. The dissolution profiles in the $0.01 \mathrm{~mol} \mathrm{~L}^{-1} \mathrm{HCl}$ medium, using molecular absorption spectrophotometry with detection at $250 \mathrm{~nm}$, showed drug release > 80\% within 10 minutes. Kumar et al. (2016) [36] in Punjab, India, formulated and evaluated nine formulations containing allopurinol with the excipients crospovidone, croscarmellose sodium, magnesium stearate and talc (also present in the formulations studied in this study), using the $\mathrm{HCl} 0.1 \mathrm{~mol} \mathrm{~L}^{-1}$ dissolution medium, by $\mathrm{UV}$ spectrophotometric method, at $250 \mathrm{~nm}$ and found dissolution $>75 \%$ of the allopurinol dose, in eight formulations. 
Tablets with a higher amount of crospovidone had a greater dissolution of allopurinol in a shorter time.

The data obtained in this study corroborate with the authors mentioned above. These same excipients are also present in the formulations of the analyzed products, which may explain the very rapid dissolution of allopurinol in tablets tested. From the results obtained for the dissolution studies (profile, kinetics, and dissolution efficiency), it is concluded that the drugs containing allopurinol met the requirements determined by the pharmacopoeias. However, this study's innovative character stands out, as no study found in the scientific literature has performed dissolution tests using HPLC-UV-DAD methods.

Table 6 shows the results obtained, following the Brazilian [8] and USP [33] pharmacopoeias, to determine average weight, friability, disintegration time, and uniformity of unit doses allopurinol tablets.

Table 6. Average weight, friability, disintegration time, and uniformity of unit doses in allopurinol tablets.

\begin{tabular}{|c|c|c|c|c|}
\hline Drug products & $\begin{array}{l}\text { Average weight } \\
(\mathrm{mg} \pm \mathrm{SD})\end{array}$ & $\begin{array}{l}\text { Friability } \\
(\text { Loss, \%) }\end{array}$ & $\begin{array}{l}\text { Disintegration time } \\
\text { (minutes and seconds) }\end{array}$ & $\begin{array}{l}\text { Uniformity of unit doses } \\
(\%)\end{array}$ \\
\hline $\mathrm{Z} 1$ & $179.7 \pm 1.3$ & 0.2 & $5,35 "( \pm 0.03)$ & $98.7-100.4$ \\
\hline $\mathrm{Z} 2$ & $543.6 \pm 0.9$ & 0.2 & 4'40”' $( \pm 0.05)$ & $97.2-100.3$ \\
\hline M1 & $175.8 \pm 0.9$ & 0.3 & 1'50" $( \pm 0.12)$ & $99.6-100.3$ \\
\hline M2 & $513.6 \pm 0.3$ & 0.3 & 1' 10" $( \pm 0.07)$ & $99.3-100.6$ \\
\hline $\mathrm{S}$ & $174.0 \pm 1.7$ & 0.2 & 4' 50”' $( \pm 0.13)$ & $97.8-101.7$ \\
\hline $\mathrm{P}$ & $537.8 \pm 1.1$ & $0 ., 2$ & 3' 29" $( \pm 0.11)$ & $99.3-100.3$ \\
\hline
\end{tabular}

SD: standard deviation

Disintegration is a physical phenomenon, and the faster this process, the more drug may be available to be dissolved in the reaction medium and later absorbed into the body, becoming bioavailable. M1 and M2 (generic drugs) showed the shortest disintegration times, which may be related to several technological factors of drug production, such as hardness and excipients present in the formulations, for example, disintegrating agents, favoring the decompression of powders [26]. Very wide variations in disintegration times can induce a difference in the drug dissolution profile and, therefore, must be taken into account in developing generic drugs [37]. The drugs showed uniform doses in production, and, therefore, these lots have quality for commercialization. The results obtained in this study corroborate with Kumar et al. (2016) [36]; Kumar and Basava Rao (2016) [38], and Moghal et al. (2016) [35], who performed the tests to determine weight, friability, and disintegration in tablets containing allopurinol.

\section{Conclusions}

A rapid and sustainable HPLC-UV-DAD method was developed and validated, in combination with chemometric tools, to determine allopurinol and obtain the dissolution profiles of allopurinol tablets. The method was validated according to guidelines (ICH and IUPAC) and applied for allopurinol tablets' assay. Allopurinol was determined in three minutes, with a total running time of 5 minutes, representing 6 times faster than a recommended race in the USP Pharmacopoeia. The allopurinol dissolution test (tablets) was optimized, reducing (10 times) the $\mathrm{HCl}$ concentration (from 0.01 to $0.001 \mathrm{~mol} \mathrm{~L}^{-1}$ ), thus contributing to the principles of green chemistry. The drugs showed first-order dissolution kinetics, and it was possible to determine the dissolution half-life, constant in the dissolution rate, the amount of allopurinol dissolved in 45 minutes, and dissolution efficiency. Therefore, this new and sustainable HPLC-UV-DAD method is friendly to the environment and can be used for allopurinol's routine pharmaceutical analysis in fixed dosage forms. 


\section{Funding}

This research received no external funding.

\section{Acknowledgments}

The authors are grateful for the financial support received (fellowships) from "Coordenação de Aperfeiçoamento de Pessoal de Nível Superior - Brasil (CAPES)", "Fundação de Amparo à Pesquisa do Estado da Bahia (FAPESB)" and "Conselho Nacional de Desenvolvimento Científico e Tecnológico (CNPq)"; for collaborations of the State University of Bahia (UNEB) and Research Group: "Biopharmaceutics and Drugs".

\section{Conflicts of Interest}

The authors declare no conflict of interest.

\section{References}

1. Sivera, F.; Andrés, M.; Quilis, N. Gout: Diagnosis and treatment. Medicina clinica 2016, 148, 271-276, https://doi.org/10.1016/j.medcli.2016.10.019.

2. Chemicalize. Allopurinol. https://chemicalize com/app/calculation/O\%3DC1N\%3DCN\%3DC2NNC\%3DC12 January 2021).

3. National Center for Biotechnology Information (NCBI). PubChem Compound Summary for CID 135401907, Allopurinol. Available online: https://pubchem.ncbi.nlm.nih.gov/compound/Allopurinol (accessed on 10 January 2021).

4. FDA. Center for Drug Evaluation and Research. NDA/BLA Multi-disciplinary Review and Evaluation. Available online: https://www.accessdata.fda.gov/drugsatfda_docs/nda/2017/209203Orig1s000MultidisciplineR.pdf (accessed on 23 January 2021).

5. Alghadi, R.; Hamadelniel, E. Biowaiver studies of seven generic brands of allopurinol $(100 \mathrm{mg})$ tablets available in Sudanese Market. Saudi Journal of Medical and Pharmaceutical Sciences 2017, 3, 1230-1236.

6. National Health Surveillance Agency. Registered product queries. Available online: https://consultas.anvisa.gov.br/\#/medicamentos/q/?substancia=624\&situacaoRegistro=V (accessed on 11 January 2021).

7. National Health Surveillance Agency. Resolution $\mathrm{N}^{\circ} 166$, Provides for the validation of analytical methods and provides other measures. Available online: http://portal.anvisa.gov.br/documents/10181/2721567/RDC_166_2017_COMP.pdf/d5fb92b3-6c6b-41308670-4e3263763401 (accessed on 09 January 2021).

8. Brazilian Pharmacopoeia (BP). Available online: http://portal.anvisa.gov.br/documents/33832/259143/IFA+e+ESP+Pronto.pdf/1d16f9e9-affc-495b-bb8f6806c2cefofe (accessed on 03 January 2021).

9. Tome, T.; Časar, Z.; Obreza, A. Development of a unified reversed-phase HPLC method for efficient determination of EP and USP process-related impurities in celecoxib using analytical quality by design principles. Molecules 2020, 25, https://doi.org/10.3390/molecules25040809.

10. Jahangirian, H.; Lemraski, E.; Webster, T.; Rafiee-Moghaddam, R.; Abdollahi, Y. A review of drug delivery systems based on nanotechnology ang green chemistry: green nanomedicine. International Journal of Nanomedicine 2017, 12, 2957-2978, https://doi.org/10.2147/IJN.S127683.

11. Dias, F.; Teles Júnior, G.; Oliveira, J.; Bonfim, D.; Santos, J.; Souza, L.; Oliveira, A.; Dias, F.S.; Santos Júnior, A. Development of a new methodology for the evaluation of in vitro dissolution of Amlodipine Besylate tablets sold in Salvador /Bahia /Brazil, using factorial experimental design. Brazilian Journal of Development 2020, 6, 14684-14703, https://doi.org/10.34117/bjdv6n3-366.

12. Kolla, S.; Vallabhaneni, M.; Puttagunta, S.; Venkata, M. Design of experiments approach to discriminatory dissolution method development of poorly soluble drug in immediate release dosage form. Indian Journal of Pharmaceutical Education and Research 2019, 53, 436-445.

13. Bos, T.S.; Knol, W.C.; Molenaar, S.R.A.; Niezen, L.E.; Schoenmakers, P.J.; Somsen, G.W.; Pirok, B.W.J. Recent applications of chemometrics in one- and two-dimensional chromatography. Journal of Separation Science 2020, 43, 1678-1727, https://doi.org/10.1002/jssc.202000011.

14. Ammar, A.; Samy, A.; Marzouk, M.; Ahmed, M. Formulation, characterization and biopharmaceutical evaluation of allopurinol tablets. International Journal of Biopharmaceutics 2011, 2, 63-71. 
15. Youssef, S.H.; Mohamed, D.; Hegazy, M.A.M.; Badawey, A. Analytical methods for the determination of paracetamol, pseudoephedrine and brompheniramine in Comtrex tablets. BMC Chemistry 2019, 13, https://doi.org/10.1186/s13065-019-0595-6.

16. Rajkumar, B.; Bhavya, T.; Ashok Kumar, A. Reverse phase HPLC method development and validation for the simultaneous quantitative estimation of alpha lipoic acid and allopurinol in tablets. International Journal of Pharmacy and Pharmaceutical Sciences 2014, 6, 307-312.

17. Singh, S.; Gadhawala, Z. Development of a stability indicating RP-RRLC method for determination of allopurinol and its degradation products in solid oral dosage. International Journal of PharmTech Research, 2013, 5, 44-53.

18. Tuzimski, T.; Petruczynik, A. Review of Chromatographic Methods Coupled with Modern Detection Techniques Applied in the Therapeutic Drugs Monitoring (TDM). Molecules 2020, 25, https://doi.org/10.3390/molecules25174026.

19. Bianchini, A.; Garlet, Q.; Rodrigues, P.; Souza, C.; Silva, L.; Dos Santos, A.; Heinzmann, B.; Baldisserotto, B. Pharmacokinetics of S-(+)-linalool in silver catfish (Rhamdia quelen) after immersion bath: an anesthetic for aquaculture. Aquaculture 2019, 506, 302-307, https://doi.org/10.1016/j.aquaculture.2019.03.044.

20. Oliveira, J.L.S.; Teles Júnior, G.A.C.; Bonfim, D.A.; Carvalho Júnior, C.M.R.; Santos, J.A.; Ferreira, M.S.; Santos Júnior, A.F. Effect of medium $\mathrm{pH}$ on in vitro dissolution of marketed tetracyclines (tetracycline and doxycycline) solid oral dosage forms in Bahia, Brazil. Dissolution Technologies 2020, 27, 32-40, https://dx.doi.org/10.14227/DT270220P32.

21. Kharat, C.; Shirsat, V.A.; Kodgule, Y.M.; Kodgule, M. A Validated RP-HPLC stability method for the estimation of chlorthalidone and its process-related impurities in an API and tablet formulation. International Journal of Analytical Chemistry 2020, 2020, https://doi.org/10.1155/2020/3593805.

22. Piponski, M.; Peleshok, K.; Logoyda, L.; Kravchuk, L.; Piatnochka, V.; Zakharchuk, U. Efficient validated HPLC/UV method for determination of valsartan and atenolol in dosage form and in vitro dissolution studies, Biointerface Research in Applied Chemistry 2020, 10, 6669-6675, https://doi.org/10.33263/BRIAC106.66696675.

23. Santos Júnior, A.; Barbosa, I.; Dos Santos, V.; Silva, R.; Caetite Junior, E. Test of dissolution and comparison of in vitro dissolution profiles of coated ranitidine tablets marketed in Bahia, Brazil. Brazilian Journal of Pharmaceutical Sciences 2014, 50, 83-89, http://dx.doi.org/10.1590/S198482502011000100008.

24. Al-Dalaen, S.M.I.; Hamad, A.W.R.; Al-Saraireh, F.; Alkaraki, R.N.; Magarbeh, M.K.M.; Abid, F.M. Bioavailability and bioequivalence of allopurinol in two tablet formulations. Biomedical \& Pharmacology Journal 2020, 13, 789-798, https://dx.doi.org/10.13005/bpj/1943.

25. Grangeia, H.B.; Silva, C.; Simões, S.P.; Reis, M.S. Quality by design in pharmaceutical manufacturing: A systematic review of current status, challenges and future perspectives. European Journal of Pharmaceutics and Biopharmaceutics 2020, 147, 19-37, https://doi.org/10.1016/j.ejpb.2019.12.007.

26. Van der Merwe, J.; Steenekamp, J.; Steyn, D.; Hamman, J. The role of functional excipients in solid oral dosage forms to overcome poor drug dissolution and bioavailability. Pharmaceutics 2020, 12,. https://doi.org/10.3390/pharmaceutics12050393.

27. National Health Surveillance Agency. Resolution $N^{o} 31$, Provides for Pharmaceutical Equivalence Studies and Comparative Dissolution Profile. Available online: https://portal.anvisa.gov.br/documents/10181/2718376/RDC_31_2010_COMP.pdf/85adb5d2-94f7-4b318b59-754ecd1ccd52 (accessed on 23 December 2020).

28. Bhakta, H.C.; Lin, J.M.; Grover, W.H. Measuring dissolution profiles of single controlled-release drug pellets. Scientific Reports 2020, 10, https://doi.org/10.1038/s41598-020-76089-z.

29. Ferreira, M.S.; Teles Júnior, G.A.C.; Carvalho Júnior, C.M.R.; Dias, F.S.; Santos Júnior, W.S.D.; Souza, M.O.G.; Santos Júnior, A.F. Evaluation of physicochemical properties and dissolution studies on quality control of low water solubility drugs (raw materials and pharmaceutical formulations). Revista Colombiana de Ciencias Químico-Farmacéuticas 2020, 49, 329-354, http://dx.doi.org/10.15446/rcciquifa.v49n2.89486.

30. VICH, ICH. ICH topic Q2 (R1), Validation of analytical procedures: text and methodology, ICH harmon, Tripart. Guidel. Available online: https://www.ema.europa.eu/en/documents/scientific-guideline/ich-q-2-r1validation-analytical-procedures-text-methodology-step-5_en.pdf (accessed on 20 December 2020).

31. Allegrini, F.; Olivieri, A. IUPAC - Consistent approach to the limit of detection in partial least-squares calibration. Analytical Chemistry 2014, 15, 7858-7866, https://doi.org/10.1021/ac501786u.

32. Hayashi, Y.; Matsuda, R.; Ito, K.; Nishimura, W.; Imai, K.; Maeda, M. Detection limit estimated from slope of calibration curve: an application to competitive ELISA, Analytical Sciences 2005, 21, 167-169, https://doi.org/10.2116/analsci.21.167.

33. United States Pharmacopoeia (USP). Monograph, Revision Bulletin, Allopurinol. Available online: http://www.pharmacopeia.cn/v29240/usp29nf24s0_m1460.html accessed on 20 December 2020).

34. Marco, B.; Rechelo, B.; Tótoli, E.; Kogawa, A.; Salgado, H. Evolution of green chemistry and its multidimensional impacts: review. Saudi Pharmaceutical Journal 2019, 27, 1-8, https://doi.org/10.1016/j.jsps.2018.07.011. 
35. Moghal, M.; Mazunder, S.; Lira, D.; Rouf, A. Fabrication and in vitro Evaluation of Allopurinol Fast Dissolving Tablets Using Croscarmellose Sodium, Sodium Starch Glycolate and Crospovidone as Superdisintegrants. Journal of Pharmaceutical Sciences 2016, 15, 73-81, https://doi.org/10.3329/dujps.v15i1.29199.

36. Kumar, R.; Nain, P.; Kaur, J.; Saini, V.; Soni, V. Formulation and Evaluation of Immediate Release Tablets of Allopurinol. International Journal of Pharmacy and Pharmaceutical Sciences 2016, 6, 238-248.

37. Markl, D.; Zeitler, A. A Review of disintegration mechanisms and measurement techniques. Pharmaceutical Research 2017, 34, 890-917, https://doi.org/10.1007/s11095-017-2129-z.

38. Kumar, G.; Basava Rao, V. Design development and in vitro characterization of allopurinol fast dissolving tablets by using various super disintegrants. Journal of Global Trends in Pharmaceutical Sciences 2016, 7, 3529-3535. 